\title{
Opacity Evaluation for Passenger Diesel Vehicle Cars in
}

\section{Tirana}

Lorenc Malka and Flamur Bidaj

Department of Energy, Polytechnic University of Tirana, Tirana 1001, Albania

\begin{abstract}
The study includes both the estimation and evaluation of the gas smoke opacity exhausted by a diesel vehicle engine and the opacity control. The evaluation and estimations were accomplished by MAHA software. This research work has been focused in the evaluation of the opacity coefficient and the sources that can influence in opacity value of the vehicles used in Albania.
\end{abstract}

Key words: Opacity coefficient, pollutant emissions, internal combustion engine, opacimeter.

\section{Introduction}

Environmental pollution caused from the transport sector is one of the main problems in Albania which rank the last country in Balkan region [1]. Based on it, Albania has a park of 445,952 vehicles of all categories and from this park, $76.6 \%$ are passenger vehicle cars. Numbers of vehicles is growing years by years, starting from 1998, numbers of vehicles is changed from 42 vehicles/1,000 inhabitants up to 121 vehicles/1,000 inhabitants as can be seen in the Table 1 .

Tirana - as a metropolitan city of Albania, has counted the largest vehicle passenger cars with $35 \%$, where $71 \%$ of them were diesel power engine. This park of vehicles is the main source of environmental pollution in Tirana. The engine pollution action manifests prominently in major urban centers which are characterized by a high vehicles density. It is observed that the peak of pollution is in the morning and the evening where the density of cars is too high in the crossroad. The smoke and gas smell in Tirana city is still outstanding issue for compression-ignition engines that keep many unknown data related to noxious origin $-\mathrm{PM}, \mathrm{CO}_{2}$ and $\mathrm{VOC}$, which due to the mixture formation processes complexity as well of combustion process. Based on it, 1,500 persons/year

Corresponding author: Lorenc Malka, Ph.D., research field: energy. E-mail: malkalorenc@yahoo.com.
Table 1 Summery of the vehicle number in relation to the inhabitants of each country [2].

\begin{tabular}{ll}
\hline Country & Nr. vehicle/1,000 inhb. \\
\hline Serbia & 227 \\
Macedonia & 144 \\
Bosnia \& Herzegovina & 135 \\
Albania & 121 \\
\hline
\end{tabular}

suffer from internal disease related directly to the environmental pollution from transport sector in Albania in accordance to Albanian Health Institute [3].

This can be improved by analyzing the situation of pollution caused from internal diesel engine and reducing the emission scale in accordance to the European standards [4], which can be seen in the Table 2.

Emission standards for passenger cars are summarized in the Table 2. Starting from the Euro 2 stage, EU regulations introduce different emission limits for diesel and petrol vehicles. Diesels engines have more stringent $\mathrm{CO}$ standards but allowed higher $\mathrm{NO}_{\mathrm{x}}$ emissions. Petrol-powered vehicles were exempted from particulate matter (PM) standards through the Euro 4 stage, but vehicles with direct injection engines will be subject to a limit of 0.005 $\mathrm{g} / \mathrm{km}$ for Euro 5 and Euro 6. Traffic-related emissions of fine particles represent one of the main sources of air pollution especially in urban areas. In particular, 
Table 2 Emission standards for passenger cars.

\begin{tabular}{|c|c|c|c|c|c|c|c|c|}
\hline Tier & Date & $\mathrm{CO}$ & THC & NMHC & $\mathbf{N O}_{\mathrm{x}}$ & $\mathrm{HC}+\mathrm{NO}_{\mathrm{x}}$ & PM & $\mathbf{P}(\# / \mathbf{k m})$ \\
\hline \multicolumn{9}{|l|}{ Diesel } \\
\hline Euro $1 \dagger$ & Jul-92 & $2.72(3.16)$ & - & - & - & $0.97(1.13)$ & $0.14(0.18)$ & - \\
\hline Euro 2 & Jan-96 & 1 & - & - & - & 0.7 & 0.08 & - \\
\hline Euro 3 & Jan-00 & 0.64 & - & - & 0.5 & 0.56 & 0.05 & - \\
\hline Euro 4 & Jan-05 & 0.5 & - & - & 0.25 & 0.3 & 0.025 & - \\
\hline Euro 5a & Sep-09 & 0.5 & - & - & 0.18 & 0.23 & 0.005 & - \\
\hline Euro $5 b$ & Sep-11 & 0.5 & - & - & 0.18 & 0.23 & 0.005 & $6 \times 10^{11}$ \\
\hline Euro 6 & Sep-14 & 0.5 & - & - & 0.08 & 0.17 & 0.005 & $6 \times 10^{11}$ \\
\hline \multicolumn{9}{|c|}{ Petrol (Gasoline) } \\
\hline Euro $1 \dagger$ & Jul-92 & $2.72(3.16)$ & - & - & - & $0.97(1.13)$ & - & - \\
\hline Euro 2 & Jan-96 & 2.2 & - & - & - & 0.5 & - & - \\
\hline Euro 3 & Jan-00 & 2.3 & 0.2 & - & 0.15 & - & - & - \\
\hline Euro 4 & Jan-05 & 1 & 0.1 & - & 0.08 & - & - & - \\
\hline Euro 5 & Sep-09 & 1 & 0.1 & 0.068 & 0.06 & - & $0.005 * *$ & - \\
\hline Euro 6 & Sep-14 & 1 & 0.1 & 0.068 & 0.06 & - & $0.005^{* *}$ & $6 \times 10^{11 * * *}$ \\
\hline
\end{tabular}

* Before Euro 5, passenger vehicles $>2,500 \mathrm{~kg}$ were type approved as light commercial vehicles N1-I;

** Applies only to vehicles with direct injection engines;

$* * * 6 \times 1,012 / \mathrm{km}$ within first three years from Euro 6 effective dates;

$\uparrow$ Values in parentheses are conformity of production (COP) limits.

diesel engines were blamed as one of the main contributors for their inherent high particulate emissions. In order to reduce the impact on human health of particulate emissions from vehicles, new stricter emission standards were considered necessary for Europe. Furthermore, research work has been focused at this group of vehicles and evaluation of the opacity factor in Tirana city.

\section{Materials and Methods}

Evaluation of opacity factor will play an important role to determine the emission scale from transport sector. Opacity is the optical term for the property of stopping light from being transmitted and when it comes to exhaust gases, it corresponds to how opaque they were. The opacity has been measured in percentage where $0 \%$ means that all light is transmitted through the media and $100 \%$ refers to the case where no light at all can pass it. Opacity is expressed by Eq. (1) which corresponds to the specific effective optical path length OPL as can be seen in Fig. 1:

$$
\mathrm{N}=100-\tau
$$

Where, $\mathrm{N}$ is the opacity in percent and $\tau$ is the ratio of transmitted light in percentage.

In addition to the evaluation of the opacity, there is a similar optical property named the light absorption coefficient. This property refers to, as the name implies, the ability to absorb light. For a homogeneous matter, the relationship between the light transmission and the light absorption coefficient is described according to the Beer-Lambert law in Eq. (2):

$$
k=-\frac{1}{L_{A}} \cdot \ln \left(\frac{\tau}{100}\right)
$$

Where, $k$ is the light absorption coefficient, $L_{A}$ is the effective optical path length and $\tau$ is the ratio of transmitted light in percent. Fig. 1a shows that OPL is the distance of media that corresponds to the opacity and how the light intensity decreases as the light passes through the sample, evaluated according to the Eq. (3):

$$
N=1-\frac{I}{l_{0}}
$$

Where, $N$ is the opacity of the gas, $I$ is the measured light intensity and $l_{0}$ is the light intensity if measured without the gas.

Measurement method was realized in accordance to 


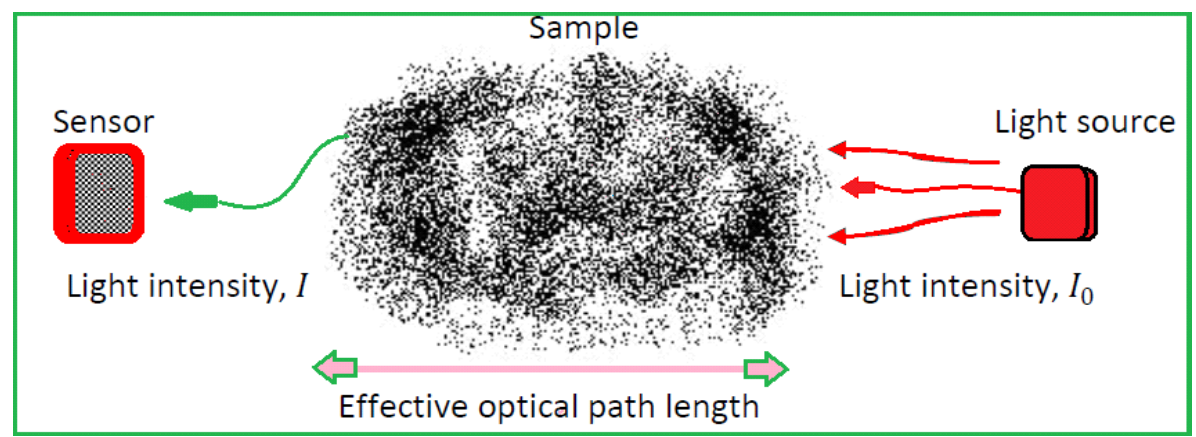

(a)

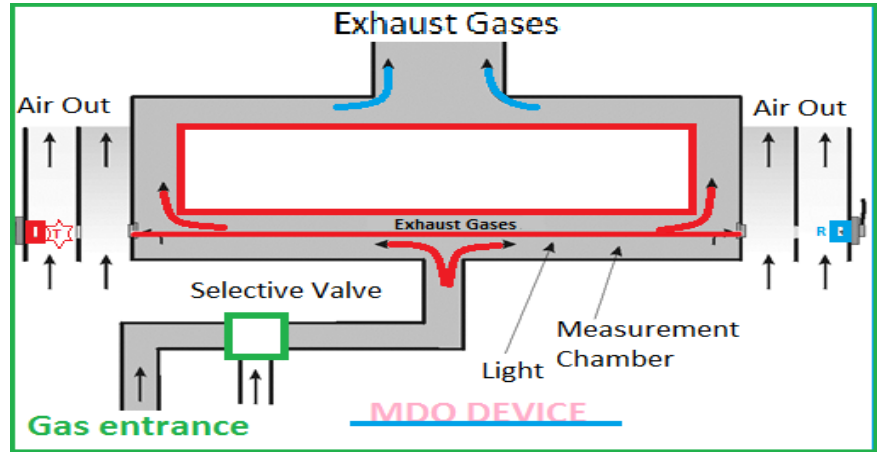

(b)

Fig. 1 (a) The figure shows the basic principle of an opacimeter and (b) the measurement principle of MDO2 opacimeter.

the Albanian Law Decision of Council of Minister 6527, dated December 24, 2004 as amended by Directive No. 12, dated June 15, 2010 and all diesel engine tests must be performed according to EU Directives 2010/48/EU for the emission in exhaust gases from diesel engines on the permissible values of the elements of air pollution from emissions and noise caused by vehicles [5]. Furthermore, in order to analyze the internal combustion engines exhaust gases, research work has used MDO2 opacimeter device where the light reduction degree was measured in the measurement chamber through which passes the gas sample, mentioned in the Figs. $1 \mathrm{a}$ and $1 \mathrm{~b}$. The emission exhaust was collected in an elongated chamber with a transmitter and receiver located at the respective ends. The transmitter consists of a LED which transmits a wave length of $567 \mathrm{~nm}$. This wave length was coordinated with the absorption capacity of the emission exhaust. A photo electric cell receives the impinging light on the opposite side of the chamber. Before starting the measurement, this device needs to be calibrated by optical lens instrument [6]. The Fig. 2 shows the example of the measurement principle of opacity.

The connection of the MDO2 device means that the measurements were ready to determine the opacity value according to the logical scheme of the Fig. 3.

The vehicles registered on or after January 1, 1980, opacity value must meet the requirement values for diesel for passenger cars category. The official emission measurement cycle in diesel vehicle passengers car category consists of at least 3 and a maximum of 5 individual measurements. The last 3 successive measurements are evaluated. After each individual measurement, there is a cleaning time of 5 seconds while the engine rotates in idle. The arithmetic mean value is calculated from the last 3 measurement exhaust strokes:

$$
k_{\text {mean }}=\frac{k_{n-2}+k_{n-1}+k_{n}}{3}
$$

Where, $n$ is the number of the last measurement exhaust stroke. 


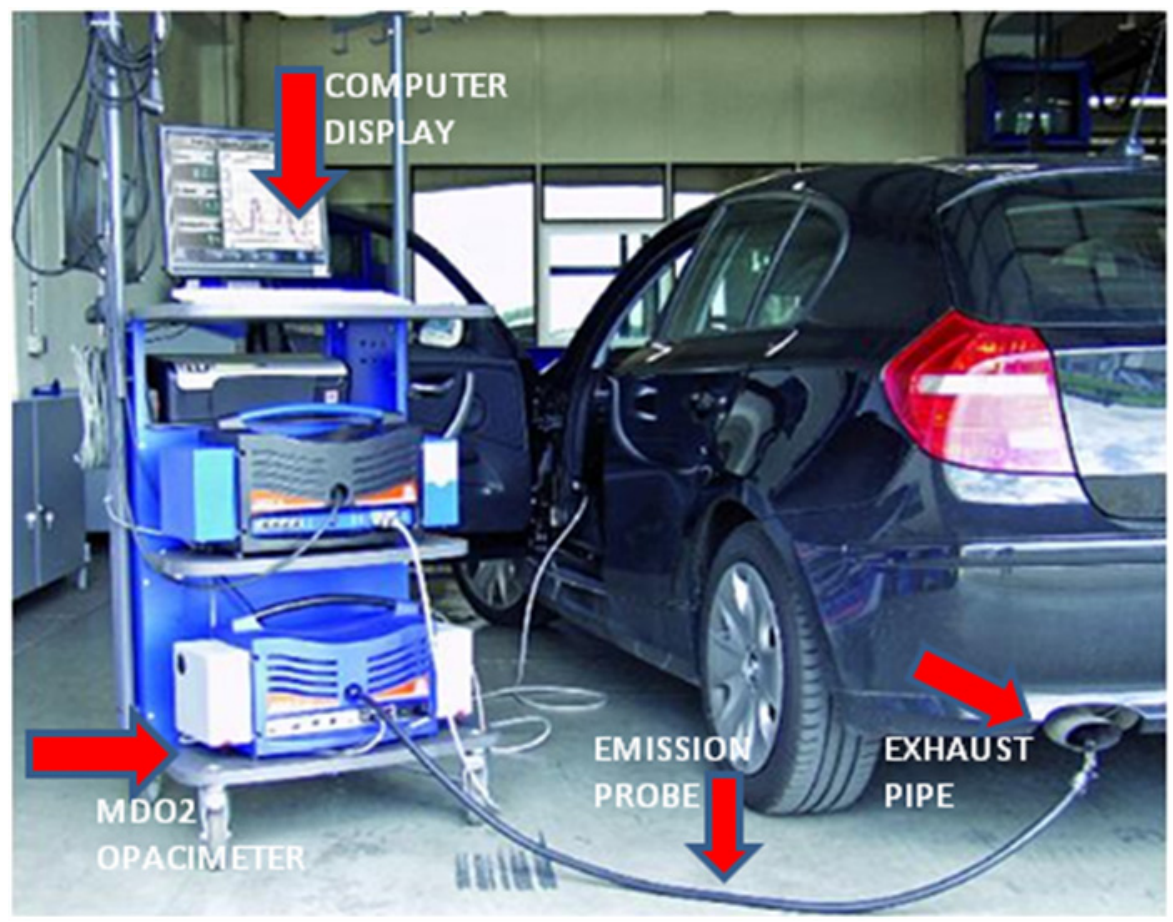

Fig. 2 Opacimeter instrument MDO2 connection with the vehicle exhaust gas pipe, located at Tirana 1 test centre.

The measurement has been completed after 3 individual measurements. If each of the individual measurement values of the first 3 measurements has a $\mathrm{k}$-value less or equal with standard, the arithmetic mean k-mean is calculated from the last 3 exhaust strokes. If all $3 \mathrm{k}$-values from which the mean value was calculated are not smaller than $60 \%$ of the k-mean, then the acceleration measurement is completed. Otherwise, the acceleration measurement is continued with two other measurement possibilities.

After the 5th exhaust stroke is done, the acceleration measurement is completed. The arithmetic mean value was calculated from the last 3 exhaust strokes:

$\mathrm{k}=<2.5 \mathrm{~m}^{-1}$ for Non Turbo Engines;

$\mathrm{k}=<3.0 \mathrm{~m}^{-1}$ for Turbo Engines.

Vehicles registered after January 7, 2008, opacity value must meet the requirement opacity value:

$$
\mathrm{k}=<1.5 \mathrm{~m}^{-1}
$$

\section{Results and Discussion}

The measurement results for evaluation of the opacity are illustrated in the Fig. 4.
The Fig. 4a shows the relation of the opacity coefficient among the production years of the different cars. From the years 1986-1990 and 1991-1995, it is seen that Volkswagen has the largest $\mathrm{k}_{\text {mean }}$ comparing to the Mercedes and other types. From the years 1996-2000 and 2001-2005, it is seen that Mercedes has the largest $\mathrm{k}_{\text {mean }}$ comparing to the Volkswagen and other types. From the years 2006-2010, it is seen that $\mathrm{k}_{\text {mean }}$ is largest for the other cars comparing to Mercedes and Volkswagen.

The Fig. 4b shows the relation between production years and results (pass/fail). The new cars have more opportunity to keep the results "pass" compare to the older cars.

The Fig. 4c shows the influence of the diesel into the opacity coefficient. The results were taken to the Seat Ibiza and the diesel taken at the same company has different scale pollution.

The Fig. 4d shows the types of the car in relation to the pollution scale. From the graph, it can be seen that the Mercedes has the highest $\mathrm{k}_{\text {mean }}$ in comparison to Volkswagen and other cars.

The Fig. $4 \mathrm{e}$ shows the relation of the produced 


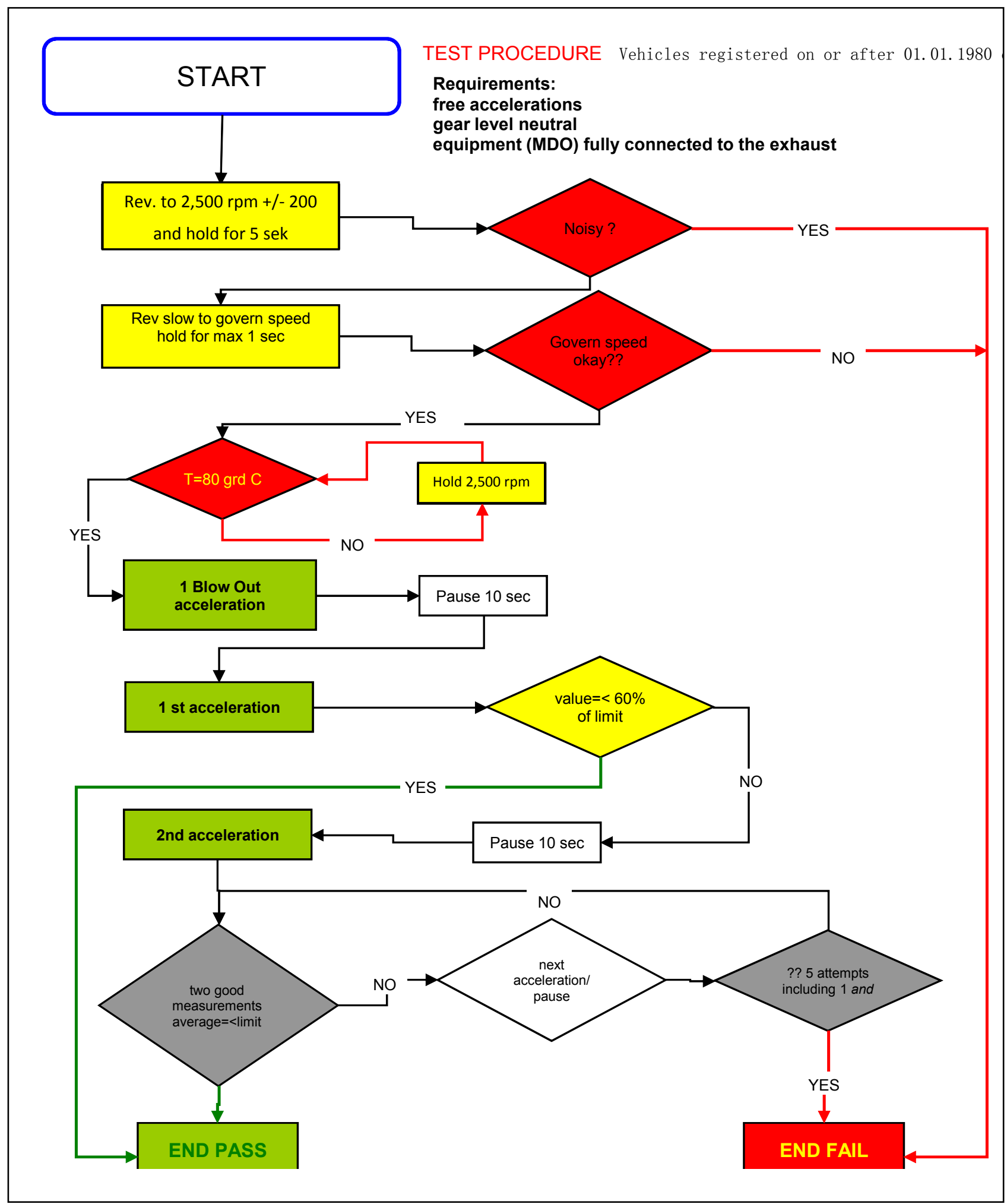

Fig. 3 Logical scheme of opacity measurement in internal diesel engine. 


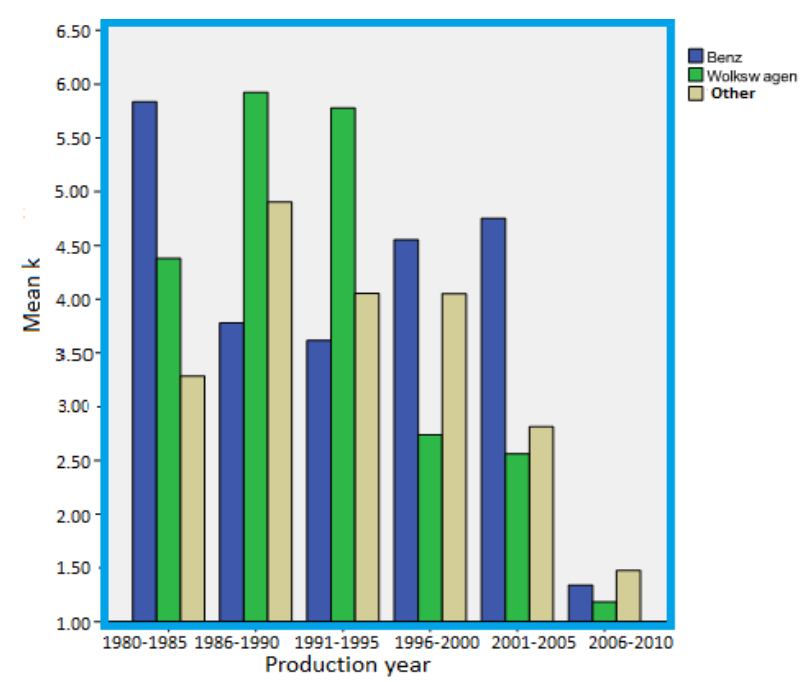

(a)

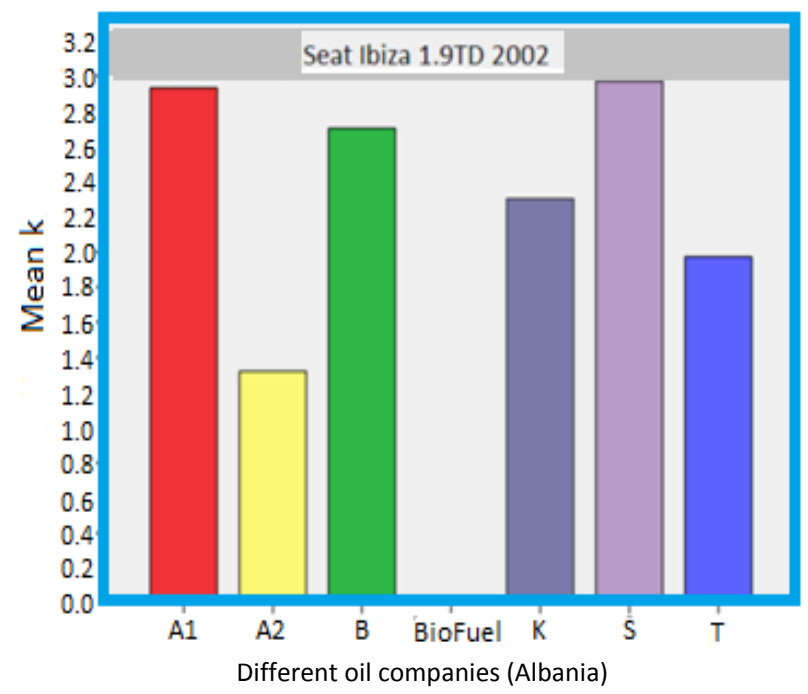

(c)

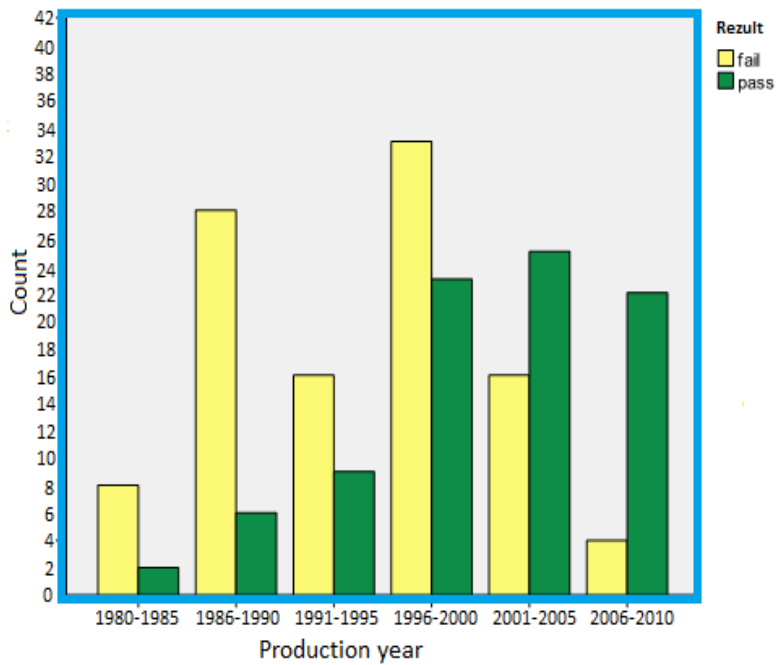

(b)

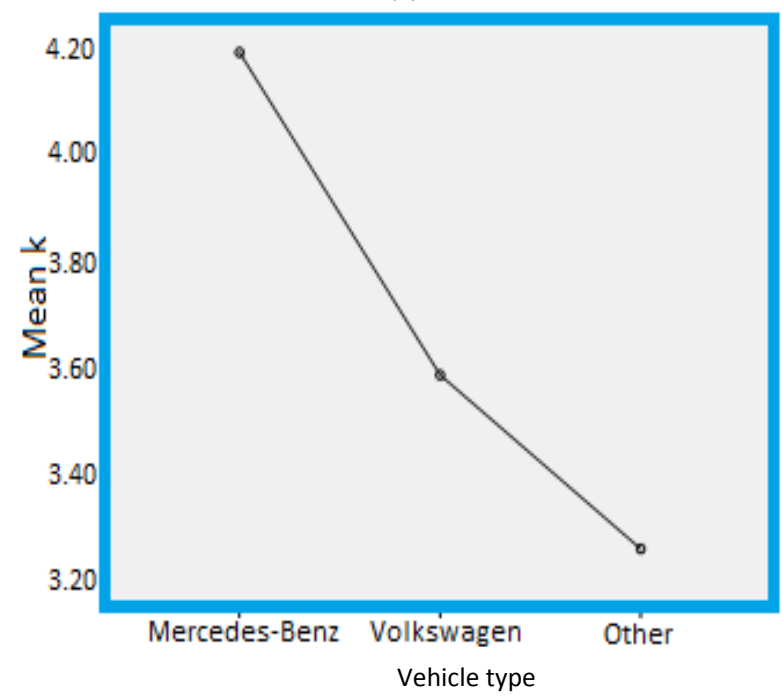

(d)

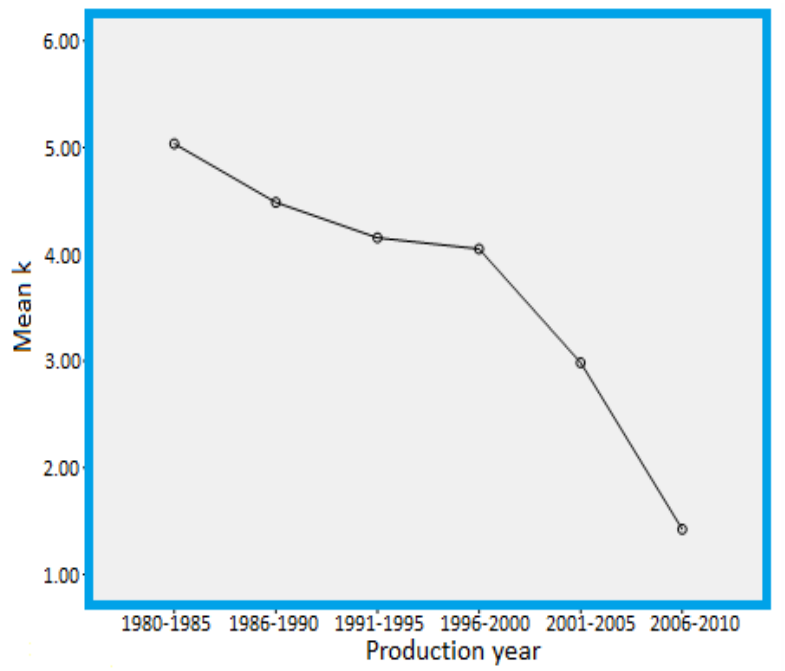

(e)

Fig. 4 Results of the opacity measurement for different types of vehicles, marks and vehicle age. 
year's car and $\mathrm{k}_{\text {mean }}$ value. The $\mathrm{k}_{\text {mean }}$ value started to be reduced for the new produced year's car.

This opacity value is a strong function of vehicle age and their type. In relation of the two main factors that influence in the scale of the opacity, the authors have taken into account the quality of the fuels through the opacity value.

\section{Conclusions}

This research work has investigated that opacity value was extremely high for the vehicles produced before 2002. Vehicles with ages more than fourteen years have very high opacity level and the most problematic groups that cause high pollution level come from the produced years 1980 up to 2002.

It has been seen that Mercedes has the highest opacity level because of their age they were introduced. It is known that the consume of specific engine oil is related with the kilometers done from the engine [7], and this is why pollution in the Mercedes types is in very high levels comparing to the others type of vehicles in Albania.

Another important factor observed from opacity evaluation can come through the quality of the fuels in Albania which is not guarantee as mentioned in the Fig. 4c. Finally, this research work has shown that the opacity value is almost twice time more than the EU standards $\left(2.5-3.0 \mathrm{~m}^{-1}\right)[8]$.

\section{References}

[1] Albanian Institute of Statistics. 2014. "Albanian Institute of Statistics Strategic Plan, 2008-2014: Environmental Situation." Accessed May 15, 2014. http://www.instat.gov.al/al/themes/mjedisi.aspx.

[2] World Bank. 2015. "World Bank Report Study, 2010-2015: Number of Cars Used in Albania Compare to the Region Countries." Accessed August 25, 2015. http://open.data.al/sq/lajme/lajm/lang/sq/id/310/Numri-iAutomjeteve-ne-Shqiperi-dhe-Krahasimi-me-Rajonin.

[3] Albanian Health Institute (ISHP). 2010. "Albanian Health Institute Report Study, 2000-2010: Pollution from the Vehicles That Influence in Health Diseases.” Accessed May 22, 2010. http://ishp.gov.al.

[4] Emission Standards for Passenger Cars. 2015. "Emission Standards for Passengers Cars Strategic Plan, 2004-2014: Summary for European Specification and Regulation for Diesel Fuel." Accessed May 1, 2015. https://www. dieselnet.com/standards/eu/fuel_automotive.php.

[5] Albanian Ministry of Environment. 2012. "Albanian Ministry of Environment Strategic Plan, 2002-2012: The Changed Law for the Older Produced Vehicles." Accessed January 22, 2012. https://www.shqiperia. com/Ndryshon-ligji-makinat-e-vjetra-dalin-nga-qarkullim i. $8312 /$.

[6] The Guideline of Gas Analyzer Device. 2009. "Gas Analyzer Device." Accessed September 18, 2009. http://www.maha.de/analyseur-de-gaz-mdo-2-lon-termina 1-portable-portable.html.

[7] Environmental Protection Agency (EPA). 2014. "EPA for Strategic Plan, 2004-2014: Global Climate Change." Accessed January 10, 2014. http://www.epa.gov/ climatechange/ ghgemissions/sources/transportation. html.

[8] European Standards for Passengers Vehicles. 2013. "Europeans Standards for Passengers Vehicles Strategic Plan, 2003-2013: Opacity Coefficients." Accessed July 29, 2013. https://www.dieselnet.com/standards/eu/ld. php. 